\title{
A Study of Mechanical Properties Evaluation for Stainless Steel Under Low Temperature Region
}

\author{
Jung Soo Oh ${ }^{1}$, Sueng Hyun $\mathrm{Cho}^{2,}{ }^{*}$, Min Young Hong ${ }^{1}$, Bong Soo Lee ${ }^{1}$ \\ ${ }^{1}$ Korea Testing Certification, Gun-po City, South Korea \\ ${ }^{2}$ Department of Electronic and Optical Engineering, Gwacheon National Science Museum, Gwa-cheon City, South Korea \\ Email address: \\ ojs82@ktc.re.kr(J. S. Oh), felicxo@naver.com (S. H. Cho), myohong@ktc.re.kr (M. Y. Hong), bs7624@ktc.re.kr (B. S. Lee)
}

\section{To cite this article:}

Jung Soo Oh, Sueng Hyun Cho, Min Young Hong, Bong Soo Lee. A Study of Mechanical Properties Evaluation for Stainless Steel Under Low Temperature Region. International Journal of Mechanical Engineering and Applications. Vol. 7, No. 2, 2019, pp. 54-57. doi: 10.11648/j.ijmea.20190702.13

Received: April 15, 2019; Accepted: May 23, 2019; Published: June 15, 2019

\begin{abstract}
For equipment operated in extreme weather regions such as Eastern Europe, Northern Russia, and Canada, etc. (with average temperature is colder than $-20^{\circ} \mathrm{C}$ during winter), measures against freezing are necessary for the materials that compose plant modules and metal materials for the components of automobiles. However, only a portion of research on the effects at high temperatures have been performed in the cases of high-speed tension tests for cryogenic materials until now with the effects at low temperature being confirmed only to the extent of the presence of differences at high and low speeds. In this study, characteristics of two universal materials for stainless steel, namely TP304 and TP316, at low temperature were examined by executing comparative tests on their mechanical characteristics at both ordinary temperature and low temperature. As a result, TP304 displayed a secondary stiffening phenomenon in the low temperature range. Meanwhile, TP316 displayed a reduction in the elongation ratio in the low temperature and it was confirmed that the maximum tensile strength increased more so than at ordinary temperature. Regarding temperature dependency, the maximum tensile strength and elongation ratio were higher for TP304, while the yield strength was higher for TP316.
\end{abstract}

Keywords: Low Temperature Region, Mechanical Characteristic, Stainless Steel

\section{Introduction}

It is required to use materials with excellent environmental resistance at low temperature. [1] The adoption of materials for machinery and parts requires the use of superior materials with high strength and cold shock characteristics especially in extreme regions, usually, the temperature reaches at $-20^{\circ} \mathrm{C}$ in wither, such as Eastern Europe, northern Russia, and Canada. [2-3]

In the case of stainless steels used in low-pressure pressure vessels with corrosion resistance, studies have been conducted to evaluate the mechanical behavior in high-temperature environments and the mechanical behavior of some super-duplex steels in low-temperature regions. However, austenitic stainless steel's mechanical behavior at low temperatures has not been studied. [4-5]

Moreover, the material properties of the cryogenic LNG storage vessel at a low-temperature environment have been conducted [6]. However, the high-speed tensile test in terms of strain rate with the respect of low temperature and high-temperature region, have been conducted. Also, a few studies had been carried at room temperature in the case of high-speed tensile tests on cryogenic materials. However, the effects at low temperatures have been confirmed only at high and low strain rate speeds. [7]

Therefore, the mechanical properties of TP304 and TP316, commonly used in austenitic stainless steels, at low temperatures have been studied in this paper.

\section{Tensile Experiment}

\subsection{Tensile Test Specimen}

Tensile test specimens used in this study were manufactured in accordance with the specifications of the No. 12B test specimen under the KS B 0801 Standard. Configuration and dimensions of the test specimens are illustrated in Figure 1 


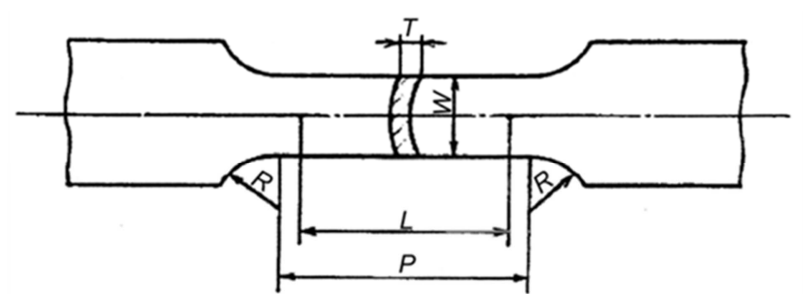

(unit, $\mathrm{mm}$ )

\begin{tabular}{c|c|c|c|c|c}
\hline TYPE & W & L & P & R & T \\
\hline TP 304 & 25 & 50 & 60 & 15 & 4.4 \\
\hline TP 316 & 25 & 50 & 60 & 15 & 4.0 \\
\hline
\end{tabular}

Figure 1. Tensile test specimen shape and dimensions.

\subsection{Test Setup}

In this study, specially-manufactured tensile test devices at low temperature illustrated in Figures $2 \& 3$ were used to execute tensile tests on experimental materials at low temperatures. A universal material test device $(300 \mathrm{kN}$, DTU-900 MHA, 380V 3ph 50/60Hz) was used, and a low temperature chamber $\left(-40\right.$ to $\left.100^{\circ} \mathrm{C}, \quad \mathrm{SP} 790\right)$ was manufactured to create a low temperature environment. An automatic temperature control system for the controlling of the temperature at consistent levels through temperature sensor and flow control installed inside the low temperature chamber. Moreover, a cryogenic elongation measurement device (3542-050M-100-ST, Epsilon Tech, -40 to $100^{\circ} \mathrm{C}$ ) was used to measure the accurate quantity of changes.

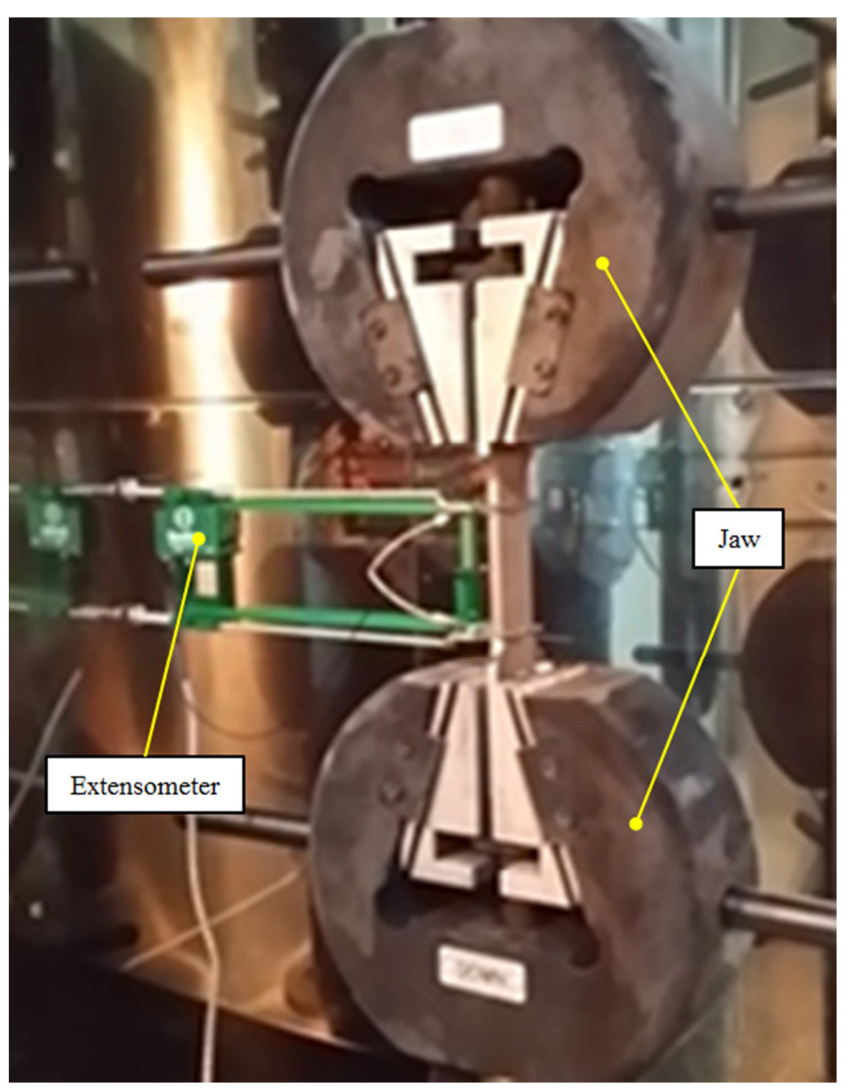

Figure 2. Tensile test under low temperature environment.

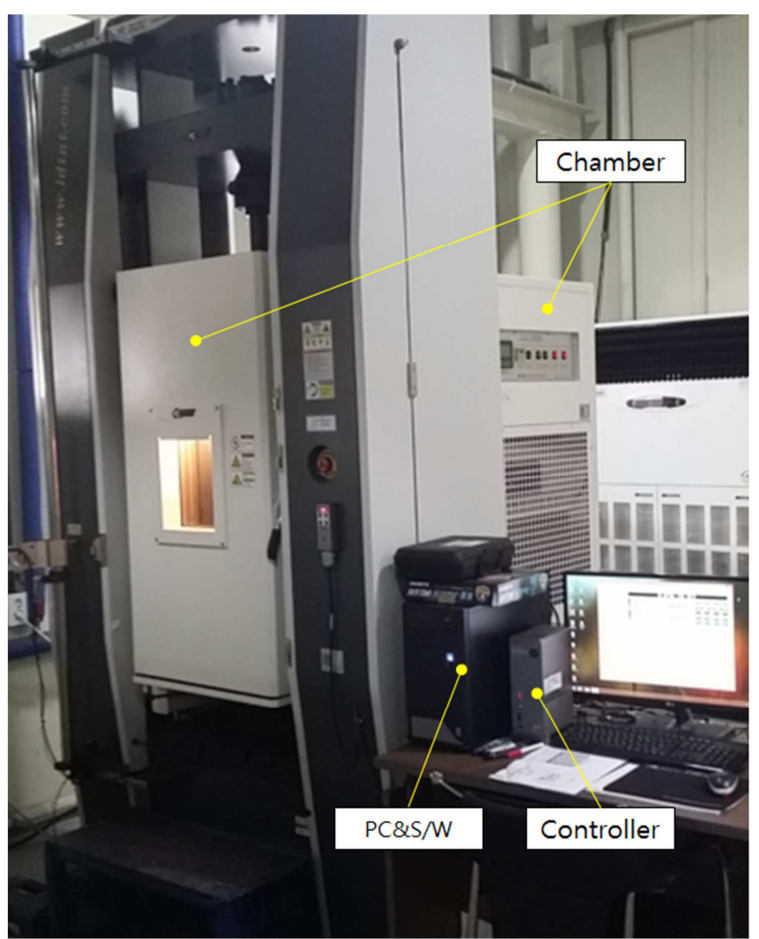

Figure 3. Low Temperature chamber and universal material testing.

\subsection{Test Conditions}

A longitudinal elongation ratio measurement device with gauge mark distance of $50 \mathrm{~mm}$ was used to measure the elongation ratio of the test specimens in the lengthwise direction as illustrated in Figure 2.

Two experimental temperatures including the ordinary temperature were set to represent extreme weather condition which the materials are used. Elongation speed in the experiment was set based on the KS B 0802. The experiment was conducted at two speeds at each temperature.

The experiment on the test specimen was conducted 10 minutes after the specimen arrived at the target temperature in order to consider the thermal equilibrium in accordance with the standards of ISO 6892-3.

Table 1. Condition of the tensile test.

\begin{tabular}{lll}
\hline Materials & Temperature $\left({ }^{\circ} \mathbf{C}\right)$ & Strain rate $(\mathbf{m m} / \mathbf{m i n})$ \\
\hline & 20 & 10 \\
TP304 & 2 \\
& -40 & 10 \\
& & 2 \\
TP316 & 20 & 10 \\
& & 2 \\
& -40 & 10 \\
\hline
\end{tabular}

\section{Experimental Results}

\subsection{Results of Tensile Test at Ordinary and Low Temperatures}

In this study, a material elongation experiment was executed for the TP304 and TP316 at both ordinary 
temperature and low temperature. Results of the experiment measured for each temperature are illustrated in Table 2.

From the results of the material elongation experiment executed, it can be seen that the elongation ratio of TP304 at ordinary temperature is a maximum of more than $64 \%$ greater than that at low temperature. It can also be confirmed that TP316 has higher elongation ratio at ordinary temperature.

Table 2. Tensile test result of TP304 and TP316.

\begin{tabular}{|c|c|c|c|c|c|}
\hline Material & Temperature & $\begin{array}{l}\text { Speed } \\
(\mathrm{mm} / \mathrm{min})\end{array}$ & $\begin{array}{l}\sigma_{T} \\
(\mathrm{MPa})\end{array}$ & $\begin{array}{l}\sigma_{T} \\
(\mathrm{MPa})\end{array}$ & $\begin{array}{l}\epsilon \\
(\%) \\
\end{array}$ \\
\hline \multirow{4}{*}{ TP304 } & \multirow{2}{*}{$20^{\circ} \mathrm{C}(293 \mathrm{~K})$} & 10 & 787.14 & 343.19 & 56.07 \\
\hline & & 2 & 780.14 & 303.60 & 80.19 \\
\hline & \multirow{2}{*}{$-40^{\circ} \mathrm{C}(233 \mathrm{~K})$} & 10 & 988.17 & 338.17 & 49.22 \\
\hline & & 2 & 1077.14 & 331.62 & 48.88 \\
\hline \multirow{4}{*}{ TP316 } & \multirow{2}{*}{$20^{\circ} \mathrm{C}(293 \mathrm{~K})$} & 10 & 587.66 & 274.91 & 75.13 \\
\hline & & 2 & 608.81 & 276.55 & 76.24 \\
\hline & \multirow{2}{*}{$-40^{\circ} \mathrm{C}(233 \mathrm{~K})$} & 10 & 730.47 & 341.65 & 69.67 \\
\hline & & 2 & 779.96 & 340.88 & 69.68 \\
\hline
\end{tabular}

\subsection{Results of Elongation Speed Comparison Experiment}

In this study, an experiment on alteration of the elongation speed between high speed $(10 \mathrm{~mm} / \mathrm{min})$ and low speed $(2$ $\mathrm{mm} / \mathrm{min}$ ) at the time of the elongation experiment on TP304 and TP316 at low temperature was executed. The results of the experiment are illustrated in Table 2 and Figures $4 \sim 8$.

Base on the results of the elongation experiment executed, there was tendency of increased yield strength and decreased maximum tensile strength with faster elongation speed. When the characteristics according to the material are examined, TP304 displayed almost no difference in elongation ratio with higher yield strength by about $2 \%$ and lower maximum tensile strength by about $8 \%$ at high elongation speed.

In the case of TP316, there is almost no difference in the elongation ratio and yield strength, and the maximum tensile strength was found to be about 7\% lower at high speed elongation. It was possible to confirm that elongation speed imparts greater influence on the maximum tensile strength in comparison to that on elongation ratio and yield strength on the basis of the aforementioned experimental results.

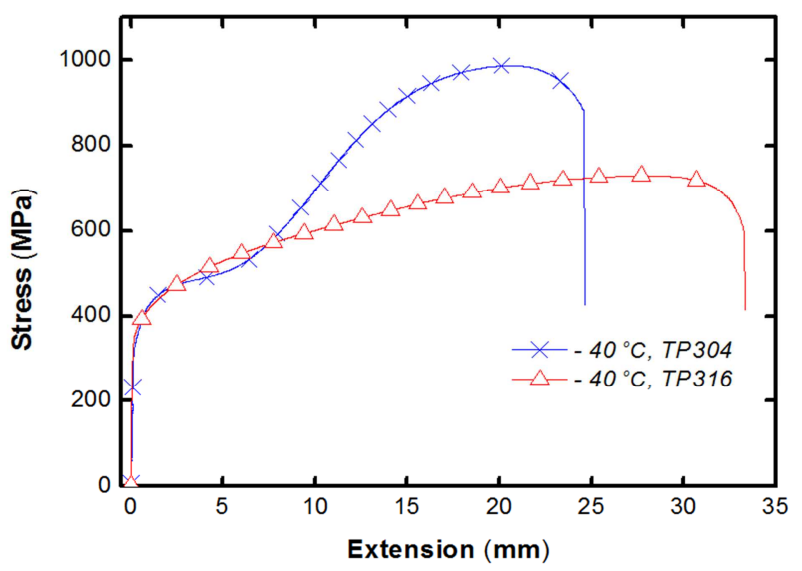

Figure 4. Comparison of TP 304 and TP 316 in Temp. $-40^{\circ} \mathrm{C}$.

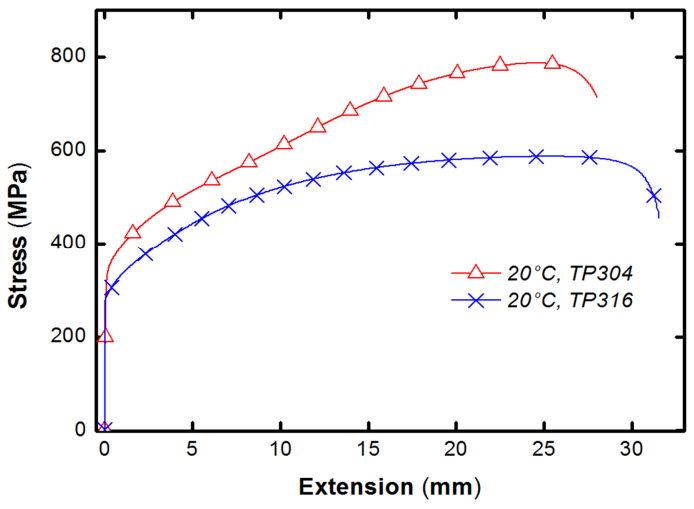

Figure 5. Comparison of TP 304 and TP 316 in Temp. $20^{\circ} \mathrm{C}$.

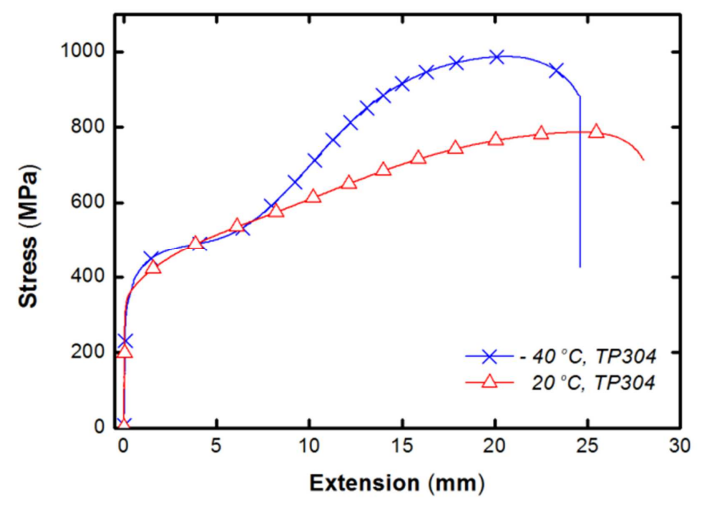

Figure 6. Comparison of $-40^{\circ} \mathrm{C}$ and $20^{\circ} \mathrm{C}$ in TP 304 .

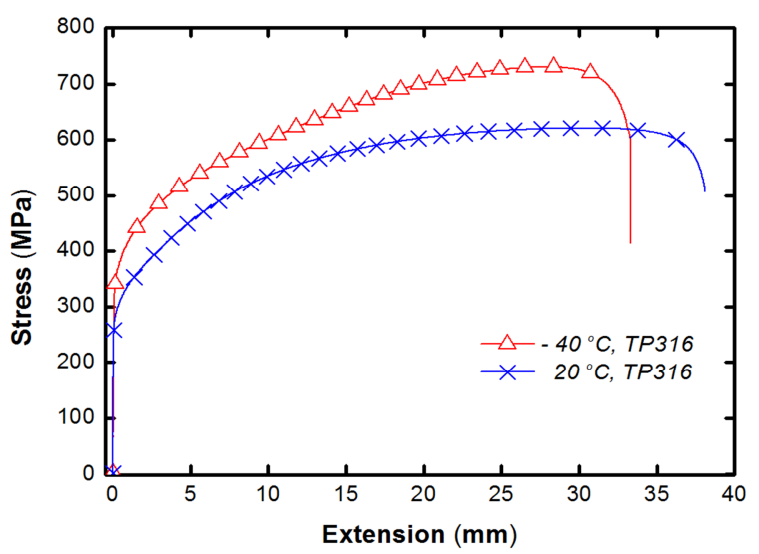

Figure 7. Comparison of $-40^{\circ} \mathrm{C}$ and $20^{\circ} \mathrm{C}$ in TP 316 .

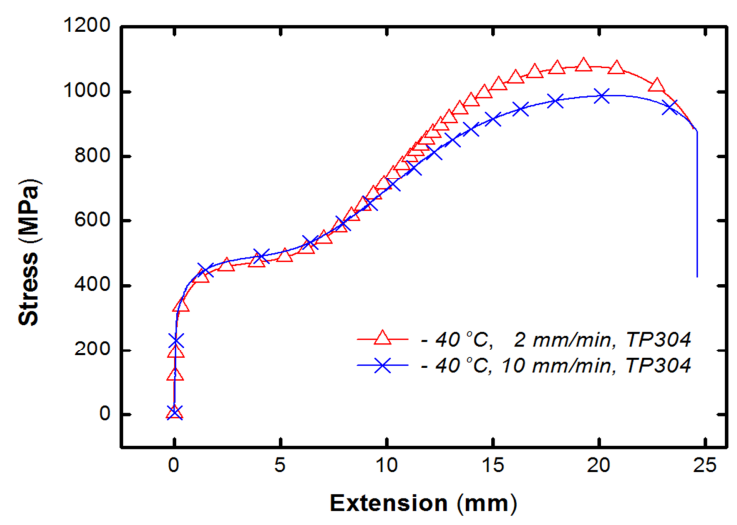

Figure 8. Comparison of Tension Speed in $-40^{\circ} \mathrm{C}, \mathrm{TP} 304$. 


\section{Conclusion}

In this study, a material elongation experiment for TP304 and TP316, which is used widely as plant and automobile materials at ordinary temperature and low temperature, and in accordance with different elongation speeds, was executed.

1) As the results of an elongation experiment on these 2 materials at ordinary and low temperatures, a secondary stiffening phenomenon in the low temperature domain occurred for TP304. It can be seen that although the elongation ratio decreases in comparison to that at ordinary temperature, the maximum tensile strength increases. Although the secondary stiffening phenomenon at low temperature domain does not occur for TP316, it was confirmed that the elongation ratio is lower and the maximum tensile strength increases at the low temperature in comparison to those at ordinary temperature.

2) It was confirmed that TP304 has greater tendency for temperature dependency than TP316.

3) As comparing the tensile speed of TP 316 and TB 304, the different tensile speed was observed. TP316 shows the increase of tensile strength and yield strength at room temperatures when tensile speed was fast. However, maximum tensile strength decreased and yield stress and elongation increased at low temperatures.

In this study, the behavior characteristics of the austenitic stainless steels owing to the temperature change in the low-temperature environment were analyzed and compared. The result of this study will be helpful to select materials for plant fabrication.

\section{Acknowledgements}

This research was supported by a grant (No. 19IFIP-B089069-06) from Technology Advancement Research Program funded by Ministry of Land, Infrastructure and Transport of Korean government.

\section{References}

[1] Gautier, D. L., Bird, K. J., Charpentier, R. R., Grantz, A., Houseknecht, D. W., Klett, T. R., Moore, T. E., Pitman, J. K., Schenk, C. J., Schuenemeyer, J. H., Sørensen, K., Tennyson, M. E., Valin, Z. C., and Wandrey, C. J. "Assessment of Undiscovered Oil and Gas in the Arctic" Science, Vol. 324, No. 5931, 2009, pp. 1175-1179.

[2] W. S. Park, K. Y. Kang, M. S. Chun, and J. M. Lee, "A comparative study on mechanical behavior of low temperature application materials for ships and offshore structures", Journal of the Society of Naval Architects of Korea, Vol. 528, 2011, pp. 189-199.
[3] J. Y. Lee, H. S. Shin, and K. T. Park, "Effects of Welding Processes on the Low Temperature Impact Toughness of Structural Steel Welded Joints", Journal of Korean Society of Steel Construction, Vol. 24, Issue 6, 2012, pp. 693-700.

[4] K. O. Lee, C. S. Ryu., S. C. Heo, and H. S. Choi, "High-Temperature Deformation Behavior of a STS 321 Stainless Steel", Journal of the Korean Society of Propulsion Engineers, Vol. 20, Issue 5, 2016, pp. 51-59.

[5] M. S. Kim, W. D Jung, J. H. Kim, and J. M. Lee, "Low-temperature Mechanical Behavior of Super Duplex Stainless Steel Considering High Temperature Environment", Journal of Ocean Engineering and Technology, Vol. 28, No. 4, 2014, pp. 306-313.

[6] J. H. Hyun, T. W. Shin, S. H. Kim, and J. H. Koh., A Study on Characteristics of Duplex Stainless Steel (ASTM A240 UNS S31803) Weld Metals made with FCAW, Journal of Welding and Joining, Vol. 35, No. 4, 2017, pp. 74-81.

[7] T. Y. Park, S. B. Jeon, M. S. Jeon, H. C. Song, K. O. Kim, and S. C. Kim, "Study on high-speed tensile test in cryogenic environment considering strain rate effect", SNAK Conference, 2012, pp. 571-576.

[8] D. G. Ahn, K. J. Moon, J. S. Kim, G. Y. Han, C. G. Jung, and D. Y. Yang, "Investigation into low-velocity impact characteristics of SUS304 sheet," Proceedings of the KSMPE Conference, 2006, pp. 111-116.

[9] K. J. Lee, T. W. Kim, J. S. Yoo, S. W. Yoo, M. S. Chun, and J. M. Lee, "Development of Temperature Dependent Damage Model for Evaluating Material Performance under Cryogenic Environment," Journal of the Society of Naval Architects of Korea, Vol. 45, No. 5, 2008, pp. 538-546.

[10] Y. K. Yoon, J. H. Kim, K. H. Baik, and C. H. Park, "Assessment for Static and Fatigue Strength of the Aluminum Alloy for LNG Ship," KSME Fall Conference, 2011, pp. 136-141.

[11] S. H. Cho, J. S. Oh, S. J. Won, and G. O. Park, "Evaluation of Mechanical Properties of Low Temperature Space for Automotive Material Applications," KSAE Annual Spring Conference, 2017, pp. 1053-1053.

[12] "ASME B31. 3: Processing Piping", The American Society of Mechanical Engineers", 2016.

[13] Kevin E. Percy, ALBERTA OIL SANDS: Energy, Industry and the Environment, Elsever, 2013.

[14] "KS B 0801: Test piece for tensile test for metallic materials", Korea Standards, 2007.

[15] "ISO 6892-3: specifies a method of tensile testing of metallic materials at temperatures between $+10^{\circ} \mathrm{C}$ and $-196^{\circ} \mathrm{C}$, International Organization for Standardization, 2015. 